\title{
A necessidade do profissional de custos nas indústrias de confecções e atacados de utilidades nas cidades de Cacoal-RO e Pimenta Bueno-RO
}

\author{
The need for cost professionals in the apparel and utility wholesale industries in the cities of \\ Cacoal-RO and Pimenta Bueno-RO \\ La necesidad de profesionales de costos en las industrias mayorista de ropa y servicios públicos en
}

las ciudades de Cacoal-RO y Pimenta Bueno-RO

Recebido: 30/11/2021 | Revisado: 06/12/2021 | Aceito: 14/12/2021 | Publicado: 22/12/2021

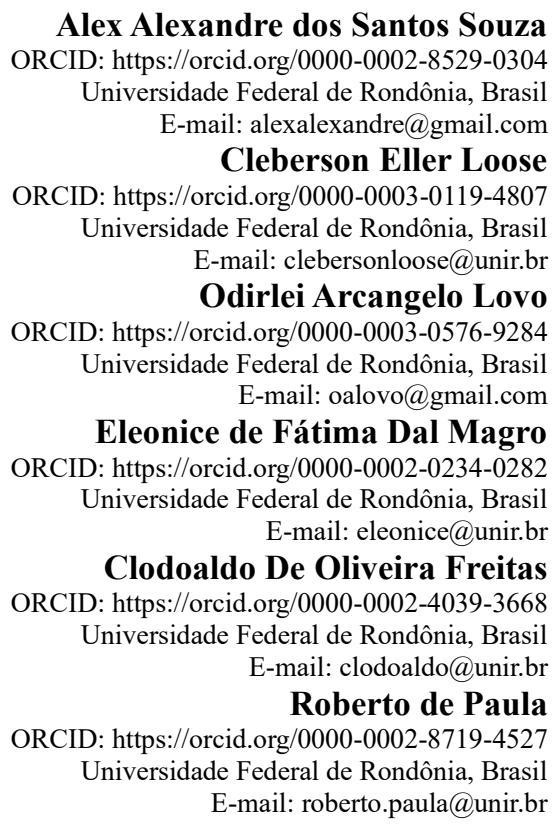

\section{Resumo}

As constantes mudanças que atingem o cenário econômico, sejam pelo surgimento de novas formas de prestação de serviço ou pelo crescimento exponencial de ferramentas tecnológicas, exigem dos empreendedores capacidades adaptativas cada vez maiores. Independentemente da atividade administrativa desempenhada, saber se posicionar frente às novas tendências do mercado é, mais do que nunca, um requisito indispensável ao sucesso de empreendimentos, e é nesse contexto que o papel exercido pelo profissional de custos se revela extremamente necessário. Isso posto, a presente pesquisa teve por objetivo recolher informações substanciais sobre o trabalho realizado por esse profissional em indústrias de confecções e atacados de utilidades nas cidades de Cacoal e Pimenta Bueno, ambas localizadas no estado de Rondônia. Não obstante muitas das organizações que participaram da pesquisa tenham o porte de microempresas e ainda não disponham de condições necessárias para manter em seu quadro de funcionários um profissional de custos embora tenha-se evidenciado a possibilidade da realização de parcerias com o intuito de obter esse tipo de consultorias -, constatou-se que a prestação desse serviço representa uma parcela significativa do sucesso das organizações que a adotam. Quanto à metodologia, foram realizadas entrevistas semiestruturadas através de formulários minuciosamente organizados sob a perspectiva da abordagem qualitativa, além do emprego do procedimento exploratório e descritivo. Tais ferramentas de pesquisa permitiram o alcance do objetivo estipulado para a pesquisa, concluindo que o profissional de custos gera mais alternativas de estratégias para os gestores, resultando maiores vantagens sobre a concorrência no mercado.

Palavras-chave: Profissional de custos; Estratégias; Gestão; Informação contábil.

\section{Abstract}

The constant changes that affect the economic scenario, whether due to the emergence of new ways of providing services or the exponential growth of technological tools, demand increasingly greater adaptive capacities from entrepreneurs, large and small. Regardless of the administrative activity performed, knowing how to position yourself in the face of new market trends is, more than ever, an indispensable requirement for the success of projects, and it is in this context that the role played by the cost professional is extremely necessary. That said, this research aimed to collect substantial 
information about the work carried out by this professional in clothing industries and wholesale utilities in the cities of Cacoal and Pimenta Bueno, both located in the state of Rondônia. Despite the fact that many of the organizations that participated in the survey are micro-enterprises and still do not have the necessary conditions to maintain a cost professional in their staff - although the possibility of partnerships in order to obtain this was highlighted. type of consultancy - it was found that the provision of this service represents a significant portion of the success of organizations that adopt it. As for the methodology, semi-structured interviews were carried out through carefully organized forms from the perspective of a qualitative approach, in addition to the use of exploratory and descriptive procedures. Such research tools allowed the achievement of the objective stipulated for the research, concluding that the cost professional generates more alternative strategies for managers, resulting in greater advantages over competition in the market.

Keywords: Cost professional; Strategies; Management; Accounting information.

\section{Resumen}

Los constantes cambios que afectan al escenario económico, ya sea por la aparición de nuevas formas de prestación de servicios o por el crecimiento exponencial de las herramientas tecnológicas, demandan cada vez mayores capacidades de adaptación de los emprendedores, grandes y pequeños. Independientemente de la actividad administrativa que se realice, saber posicionarse ante las nuevas tendencias del mercado es, más que nunca, un requisito indispensable para el éxito de los proyectos, y es en este contexto que el rol que juega el profesional de costos es sumamente importante. necesario. Dicho esto, esta investigación tuvo como objetivo recabar información sustancial sobre la labor que desarrolla este profesional en las industrias de confección y servicios mayoristas en las ciudades de Cacoal y Pimenta Bueno, ambas ubicadas en el estado de Rondônia. A pesar de que muchas de las organizaciones que participaron en la encuesta son microempresas y aún no cuentan con las condiciones necesarias para mantener un costo profesional en su personal, aunque se destacó la posibilidad de alianzas para lograrlo. Tipo de consultoría - Se encontró que la prestación de este servicio representa una parte significativa del éxito de las organizaciones que lo adoptan. En cuanto a la metodología, las entrevistas semiestructuradas se realizaron a través de formularios cuidadosamente organizados desde la perspectiva de un enfoque cualitativo, además del uso de procedimientos exploratorios y descriptivos. Dichas herramientas de investigación permitieron el logro del objetivo estipulado para la investigación, concluyendo que el profesional de costos genera más estrategias alternativas para los gerentes, resultando en mayores ventajas sobre la competencia en el mercado.

Palabras clave: Costo profesional; Estrategias; Gestión; Información de cuenta.

\section{Introdução}

A informação contábil vem galgando cada vez mais espaço no ambiente organizacional, pois as informações que são entregues são de suma importância para o mantimento e desenvolvimento das empresas, mantimento pelo fato do controle de toda a situação patrimonial da entidade, e desenvolvimento por todas as informações que podem ser usufruídas pelos administradores, para novas estratégias e tomadas de decisões, alcançando assim o crescimento (Filho \& Moura, 2016).

A contabilidade de custos é de suma importância para a tomada de decisão, por possibilitar o acesso a importantes dados que auxiliam os gestores a se organizarem melhor, e buscarem uma melhor forma de gerenciar os setores das empresas. Por esse motivo vem desempenhando um papel fundamental no momento da tomada de decisões uma vez que com a globalização, a competitividade vem aumentando de forma significativa e, com isso fazendo com que as empresas tenham um melhor desempenho para superar as concorrências (Martins, 2018).

As empresas buscam cada vez mais o controle sobre suas informações contábeis, e a contabilidade gerencial tem sido uma grande auxiliar, fornecendo ferramentas que ajudam os gestores a tomar as melhores decisões, sendo que Rocha, Nobre e Araújo (2018) enfatizam que dentre todas as ferramentas destaca-se o orçamento, o fluxo de caixa e o ponto de equilíbrio. De acordo com os autores, as informações que esses instrumentos fornecem os gestores estes conseguem ter uma visão ampla de toda a situação da organização, acarretando assim maior segurança na tomada de decisões.

Conforme Casado, Paulino e André (2018), os profissionais especializados em custos estão sendo cada vez mais necessários e exigidos dentro das empresas, pois diante de mercados cada vez mais globalizados é natural que esses profissionais precisem ser multifacetados para um melhor desenvolvimento das operações das entidades.

Isto posto, afere-se que a contabilidade de custos e uma leitura e interpretação adequada de seus resultados possam melhorar consideravelmente os resultados de uma empresa, fornecendo aos gestores controle e segurança nas tomadas de 
decisões. Nessa perspectiva, a presente pesquisa propôs-se a responder ao seguinte questionamento: os atacados de utilidades e indústrias de confecção dos municípios de Cacoal e Pimenta Bueno, em Rondônia, possuem profissionais especialistas em custos? Em caso afirmativo, qual o benefício gerado para a organização? Para responder as referidas questões, após uma revisão bibliográfica, foi realizada uma entrevista semiestruturada por meio de pesquisa de campo, no intuito de contribuir com o conhecimento teórico e prático sobre a importância da atuação de um profissional de custos dentro das organizações com vistas a melhores resultados nas indústrias têxteis e atacados de confecções de Cacoal e Pimenta Bueno, municípios localizados na região centro-leste do estado de Rondônia.

\section{Metodologia}

A metodologia da presente pesquisa em relação a sua natureza se caracteriza como aplicada por ter como objetivo a produção de conhecimento para a aplicação prática, direcionado à elucidação de problemas específicos com interesses locais (Gerhardt \& Silveira, 2009). Quanto à abordagem, ela se configura como qualitativa, pelo fato de que não será dada uma atenção específica a dados numéricos, mas no porquê da utilização ou não dos serviços dos profissionais de custos. A abordagem qualitativa tem como objetivo compreender o porquê de acontecimentos, e diante disso os dados apurados são não métricos se valendo de diferentes abordagens (Gerhardt \& Silveira, 2009).

Quanto aos objetivos a pesquisa se caracteriza como exploratória e descritiva, destacando-se que a pesquisa exploratória objetiva apresentar uma visão ampla aproximada da situação que motiva a pesquisa na intenção de esclarecer, desenvolver e transformar conceitos e ideias, e a pesquisa descritiva têm como propósito estudar as peculiaridades de determinado grupo, descrevendo também as características de determinado fenômeno ou população, conforme argumenta Gil (2008).

O método utilizado é o dedutivo por ser o mais indicado para a presente pesquisa, uma vez que segundo Lakatos e Marconi (2003) o método dedutivo tem por fito esclarecer o conteúdo das premissas, ou seja, reformula ou expressa de modo compreensível informações já existentes. Silva (2017, p. 39) enfatiza que de acordo com tal método, os enunciados universais são transformados em particulares, pois o "ponto de partida é a premissa antecedente, que tem valor universal e o ponto de chegada é o consequente (premissa particular)."

A coleta de dados foi realizada nos municípios de Cacoal e Pimenta Bueno - na região centro-leste do estado de Rondônia, de forma especifica nos atacados de utilidades e indústrias de confecção, tendo como participantes os gestores de empresas atacadistas e indústrias têxteis. Utilizou-se como instrumento para coleta de dados foi o questionário, e todas as informações da presente pesquisa foram analisadas, agrupadas e organizadas por meio de ferramentas eletrônicas, em especial Word e Excel, para posteriormente serem apresentadas em formas de quadros e gráficos para uma melhor interpretação e discussão dos resultados obtidos, no intuito de apresentar uma resposta ao problema apontado.

\section{Resultados e Discussão}

Nesta seção é apresentada uma revisão de literatura abordando questões como: informação contábil, contabilidade gerencial para tomada de decisão, contabilidade de custos, métodos de custeio e contabilidade de custos para tomada de decisões.

\subsection{Informação contábil}

A informação contábil é de suma importância para a boa gestão de uma empresa, pois é a partir das demonstrações contábeis que os gestores terão acesso às informações sobre a saúde financeira da empresa. Silva e Campos (2020) asseveram que os relatórios contábeis revelam aos gestores a situação financeira que a empresa se encontra, permitindo assim que estes realizem as análises necessárias para tomarem as decisões mais acertadas.

Conforme o CPC de número 26 (CFC, 2011), as demonstrações contábeis têm por objetivo “proporcionar informação 
acerca da posição patrimonial e financeira, do desempenho e dos fluxos de caixa da entidade que seja útil a um grande número de usuários em suas avaliações e tomada de decisões econômicas”. É fato que a informação contábil precisa ser de fácil entendimento para todos os usuários que necessitam buscar informações nos relatórios e nas demonstrações contábeis, pois são nesses documentos que os investidores e gestores irão se apoiar para as tomadas de decisão, por exemplo.

As características qualitativas de melhoria ajudam na utilidade das informações dos relatórios financeiros das empresas, e uma dessas características qualitativas é a compreensibilidade, por apresentar as informações de modo claro e conciso, ajuda na compreensão dos relatórios, mas nem sempre é possível extrair informações de fenômenos financeiros dos relatórios que dificultam o entendimento, sendo necessário o auxílio de consultor para compreender as informações (CPC 00, 2011). Silva e Santos (2020) corroboram ao afirmar que os relatórios financeiros tem por objetivo fornecer informações relevantes e verdadeiras para seus usuários sobre toda a estrutura financeira e patrimonial da entidade, para uma segurança maior na tomada de decisão.

Um grande problema enfrentado é que em muitas empresas a informação contábil não é utilizada de forma frequente pela gestão como deveria ser, e isso traz uma sensação de que a informação contábil só serve para as entidades governamentais. "Parte do problema tem se dado na transferência do core da função contábil (informação destinada à decisão) para a 'certificação da informação', que se refere à credibilidade da informação para fins de planejamento público pelo Estado e com fins fazendários" (Gilho \& Moura, 2016, p. 72).

\subsection{Contabilidade gerencial para tomada de decisão}

Empresas necessitam de uma gestão pontual e eficiente nas tomadas de decisão, pois é nesse momento que os caminhos e estratégias são traçados para o crescimento da organização, a contabilidade gerencial é um ramo do conhecimento da contabilidade voltado exclusivamente para atender as necessidades dos usuários, pois é por meio de suas ferramentas que são levantados os dados para as tomadas de decisão. A contabilidade gerencial é a área da contabilidade que tem como finalidade conceder informações contábeis aos gestores das organizações, para direcioná-los em suas funções de gerenciamento (Rocha, Nobre \& Araújo, 2018).

Segundo Zahaikevitch et al. (2018), a contabilidade gerencial é uma importante ferramenta no processo de tomada de decisão dentro da empresa, porque ela não é apenas uma contabilidade voltada a suprir uma exigência fiscal, mas aquela que auxilia o gestor a entender toda a situação da empresa, fazendo assim uso das informações da organização geradas pela contabilidade para planejar melhor as estratégias futuras a serem adotadas.

De acordo com Corrêa \& Schio (2017), as informações contábeis precisam ser usadas no processo gerencial da empresa, pois se as informações que a contabilidade gera não são usadas nesse processo não é possível fazer um planejamento, controle e nem avaliação de desempenho, com isso a contabilidade gerencial não existe na organização, porque a contabilidade gerencial é uma ação e não uma técnica especifica. As ferramentas gerenciais são de suma importância para a gestão por auxiliarem a gerência das empresas a planejarem o que deve ser feito, assessorando nas decisões que precisam ser tomadas e consequentemente possibilitando obter mais segurança e confiabilidade em seus resultados, além de contribuírem com a definição de estratégias de gestão que possibilitem a empresa alcançar seus objetivos, desde que as ferramentas gerenciais estejam entrelaçadas com a missão e visão da empresa (Santos; Degliuomeni; Camargo \& Guse, 2020).

O Quadro 1, apresenta algumas ferramentas gerenciais disponibilizadas aos gestores quando da adoção da contabilidade gerencial, ao passo que abarcam desde àquelas utilizadas na elaboração do planejamento estratégico até o sistema de informação gerencial adotado pela empresa ou organização. 
Quadro 1: Ferramentas Gerenciais.

\begin{tabular}{|c|c|}
\hline Ferramenta & Definição \\
\hline $\begin{array}{c}\text { Missão } \\
\text { Organizacional }\end{array}$ & $\begin{array}{l}\text { Quando ocorre a formulação da missão de uma entidade, seja ela uma área, seja uma empresa como um todo, devem- } \\
\text { se considerar os seguintes pontos: valores fundamentais da entidade, produtos e serviços oferecidos, mercados de } \\
\text { atuação e clientela a ser atendida (Oliveira, 2009) }\end{array}$ \\
\hline $\begin{array}{c}\text { Visão } \\
\text { Organizacional }\end{array}$ & $\begin{array}{l}\text { O conceito de visão é amplo, contudo, pode ser definido como um conceito operacional que tem como objetivo a } \\
\text { descrição da autoimagem da organização, ou seja, a maneira pela qual ela gostaria de ser vista (Costa, 2007) }\end{array}$ \\
\hline $\begin{array}{c}\text { Valores } \\
\text { Organizacionais }\end{array}$ & $\begin{array}{l}\text { Os valores são crenças que servem de princípios para os comportamentos, atitudes e decisões de todas as pessoas } \\
\text { dentro das organizações, no que tange a responsabilidade e alcance dos objetivos. Os valores facilitam a colaboração } \\
\text { dos indivíduos no desenvolvimento da missão e visão, e isto resulta no comprometimento entre a equipe e a } \\
\text { sociedade. }\end{array}$ \\
\hline Custos & $\begin{array}{l}\text { A contabilidade de custos tem a finalidade de auxiliar na "avaliação dos estoques; apuração dos resultados; controle } \\
\text { das atividades produtivas e tomada de decisão" (Cherman, 2002, p.10). }\end{array}$ \\
\hline Flux & $\begin{array}{l}\text { Relaciona-se com o conjunto de entradas e saídas de recursos financeiros da empresa em um determinado período, } \\
\text { indicando como será o saldo do caixa para o período planejado. É de grande importância dentro das empresas, visto } \\
\text { que é uma ferramenta que auxilia o monitoramento da área financeira, para analisar e constatar quando os fatores } \\
\text { podem gerar falta de recursos, e consequentemente o desequilíbrio financeiro (Marques, 2010). }\end{array}$ \\
\hline Benc & $\begin{array}{l}\text { É uma ferramenta gerencial que serve para assessorar os gestores da empresa a identificar as melhores práticas } \\
\text { existentes em empresas líderes e adotá-las, ou seja, observam atentamente as práticas das outras organizações como } \\
\text { exemplos de melhoria. }\end{array}$ \\
\hline $\begin{array}{c}\text { Balanced } \\
\text { Scorecard - BSC }\end{array}$ & $\begin{array}{l}\text { É um instrumento de gestão que integra as medidas derivadas da estratégia, essas medidas são divididas de forma a } \\
\text { incorporar quatro aspectos fundamentais: perspectiva do cliente, dos processos internos e do aprendizado e } \\
\text { crescimento (Kaplan e Norton, 1997). }\end{array}$ \\
\hline $\begin{array}{c}\text { Sistemas de } \\
\text { Informações } \\
\text { Gerenciais - BSG }\end{array}$ & $\begin{array}{l}\text { Um sistema de informação contábil gerencial tem necessariamente que abranger todas as áreas de contabilidade que } \\
\text { se vale o conceito de contabilidade gerencial. Além disso, o sistema tem que incorporar todos os dados quantitativos } \\
\text { necessários para a mensuração e análise concatenada das informações com o momento operacional da empresa } \\
\text { (Padoveze, 1997). }\end{array}$ \\
\hline
\end{tabular}

Fonte: Santos, Degliuomeni, Camargo e Guse, (2020, p. 169-170).

Em função da contabilidade de custos estar diretamente associada à tomada de decisão, é preciso que seja executada de forma organizada e ordenada para que as decisões tomadas pela gestão sejam pontuais e mais assertivas (Zahaikevitch, 2018).

\subsection{Contabilidade de custos}

Até o fim do século XIX os gestores não tinham preocupação com os custos, surgindo nas indústrias têxteis, mesmo que as grandes empresas da época fossem as siderúrgicas e as ferrovias, mas o que causou um grande impulso na busca de um cuidado maior com os custos foram os engenheiros adeptos da administração cientifica, pois começaram a perseguir a eficiência dos processos de produção (Gimenez, Oliveira \& Carvalho, 2018).

De acordo com Martins (2018), a contabilidade de custos surgiu na revolução industrial, pelo fato de que antes as empresas eram basicamente comércio, pois na época quase todos os bens eram produzidos por pessoas ou grupos de pessoas que raramente constituíam empresa, nisso com o surgimento das indústrias foi necessário novas adaptações e novas técnicas de contabilidade para controle de produção e estoque, criando assim a contabilidade de custos.

Conforme Oliveira, Duarte e Duarte (2020), a contabilidade de custos é voltada para o controle e analise de gastos que uma entidade realiza, e surgiu pela grande demanda por mais controle e informações precisas dos gastos, haja vista que com o advento da revolução industrial os processos foram ficando cada vez mais complexos e de difícil controle.

Segundo Martins (2018), quando são colocados os termos da contabilidade de custos os iniciantes se veem perdidos e os experientes embaraçados, pois são diversos termos que muitas vezes confunde quem irá utilizar a informação. 
Quadro 2: Ferramentas gerenciais: terminologias da área de custos.

\begin{tabular}{|l|l|}
\hline Gasto & $\begin{array}{l}\text { Compra de um produto ou serviço qualquer, que gera sacrifício financeiro para a entidade (desembolso), sacrifício } \\
\text { esse representado por entrega ou promessa de entrega de ativos (normalmente dinheiro). }\end{array}$ \\
\hline Desembolso & $\begin{array}{l}\text { Pagamento resultante da aquisição do bem ou serviço. Pode ocorrer antes, durante ou após a entrada da utilidade } \\
\text { comprada, portanto defasada ou não do momento do gasto. }\end{array}$ \\
\hline Investimento & Gasto ativado em função de sua vida útil ou de benefícios atribuíveis a futuro(s) períodos(s). \\
\hline Custo & Gasto relativo a bem ou serviço utilizado na produção de outros bens ou serviços. \\
\hline Despesa & Bem ou serviço consumido direta ou indiretamente para a obtenção de receitas. \\
\hline Perda & Bem ou serviço consumidos de forma anormal e involuntária. \\
\hline
\end{tabular}

Fonte: Martins (2018, p. 10-11).

De acordo com Soares e Barbieri (2017), a classificação dos custos é fundamental para uma correta analise das informações colhidas, pois por meio desses resultados os gestores compreendem como programar o melhor método de custeio para uma produção, ou mesmo para prestações de serviço.

\subsection{Métodos de custeio}

Há diversos sistemas de custeio que são utilizados tanto na indústria quanto no comércio, pois em cada entidade os custos são gerenciados de acordo com as especificidades da organização, e o sistema de custeio deve ser escolhido conforme a necessidade do custeamento que o gestor da empresa identifica ser o adequado (Ribeiro, 2015).

O custeio por absorção tem como característica atribuir todos os custos ao produto ou prestação de serviço, sendo os custos diretos, indiretos, fixos e variáveis, é o sistema mais tradicional usado e o permitido para fins contábeis, porém para a formação do preço de venda de um produto no contexto atual. O método por absorção tem sido de difícil ajuste, por que os custos e despesas fixas assumiram uma proporção de grande importância no custo final dos produtos, e atualmente a formação do preço de venda não vem sendo apenas com base nos custos e despesas internas da empresa, mas também por uma função externa que são os concorrentes (Santos, Schmidt, Pinheiro \& Nunes, 2015).

Ao contrário do custeio por absorção há o custeio variável, que atribui aos produtos apenas os custos variáveis, esse método não é valido para balanços e demonstrações contábeis, pois fere as normas contábeis por deixar de lado os custos fixos e usá-los como despesas na contabilidade. O método custeio por absorção é muito usado pelos gestores, pelo fato de apresentar resultados vitais para a administração muito mais rápido em comparação ao método de absorção, pois quando verificamos o resultado final do período é possível observar que o lucro no custeio variável sempre acompanha as vendas, e isso não ocorre pela absorção necessariamente (Martins, 2018).

O método de Custeio Baseado em Atividades (ABC) tem como característica a apropriação de todos os custos diretos e indiretos, sendo eles fixos ou variáveis nas mercadorias, produtos e serviços, e em relação ao custeio por absorção e o variável esse sistema é intermediário entre os dois, pois não é tão engessado quanto o primeiro e também não tão flexível como o segundo, esse método é o mais recente, pois sua operacionalidade é ligada a tecnologia da informação (TI), pois seu controle é mais rígido e sem o advento da informática seria inviável sua operação devido ao controle rígido (Santos et al., 2015).

De acordo com Marins (2018), não se pode ser sempre contra um determinado método de custeio, pois todos possuem suas falhas e méritos, o ideal seria na medida do possível, que as empresas tivessem um sistema suficientemente flexível, que pudesse desfrutar de todas as informações necessárias que esses métodos proporcionam para uma melhor gestão dos custos, pois se existisse um método absolutamente perfeito não seria necessário o estudo dos outros pelo simples fato que já teriam sumido da literatura e da prática.

\subsection{Contabilidade de custos para tomada de decisões}

Segundo Martins (2018), nas últimas décadas a contabilidade de custos deixou de ser uma mera auxiliar no controle dos 
estoques e de lucros, para assumir um importante papel que é assessorar no controle e decisões gerenciais, que são suas duas funções mais relevantes nesse seu novo campo de atuação.

A contabilidade de custos é um importante instrumento para os gestores, pois ela caminha junto com a contabilidade gerencial, fornecendo dados relativos a gastos, custos e despesas dos produtos, e ajuda na precificação e controle de estoque nas empresas. "A correta análise dos custos, preços e valores possibilita um processo mais coerente de tomada de decisão, e são premissas relevantes da contabilidade gerencial" (Oliveira, Duarte \& Duarte, 2020).

Para Carvalho e Mota (2019), a utilização dos custos na formação do preço de produtos e serviços é uma das técnicas mais utilizadas, mas é preciso ter cautela com os dados, pois é de extrema importância que seja realizado corretamente o cálculo do preço, sabendo alocar precisamente os custos ao produto, e utilizando técnicas de rateio para conseguir determinar melhor o custo do produto para a empresa, e assim chegar ao preço de venda correto.

Nas últimas décadas as empresas tem feito grandes esforços para se garantir competitivas no mercado, pois a cada ano que passa a concorrência vem aumentando de forma expressiva, fazendo com que as organizações, independentes do porte, fiquem na pressão para colocar produtos de qualidade e preços competitivos, e a gestão de custos tem sido de fundamental importância para ajudar as empresas na manutenção dos lucros e competitividade no mercado (Zanin, Magro \& Mazzioni, 2019).

É notável que a contabilidade de custos tenha se tornado uma ciência importante no campo empresarial, pois fornece muitas ferramentas que ajudam as entidades a se organizarem melhor com as informações apresentadas, sendo assim produzindo resultados que trazem inúmeros benefícios, gerando um grande impacto organizacional nas entidades (Nerio, 2020).

\subsection{Formação do preço de venda}

Toda entidade quando faz o levantamento do preço de venda de seus produtos espera que com a venda recupere no mínimo os custos e despesas variáveis que estão adicionados aos mesmos, e que cubra também uma parte dos custos e despesas fixas da empresa, para que a partir desse ponto, possa ter a margem de lucro desejada para o retorno de capital investido e para a remuneração desse capital em quantidade igual ou superior aos juros que são usados no mercado (Ribeiro, 2015).

$\mathrm{Na}$ formação do preço de venda dos produtos muitos usam a diferença do valor dos custos e despesas fixas com o valor do preço de venda do produto como lucro da empresa, mas o que realmente deve ser levado em conta é a margem de contribuição do produto, que é a diferença do preço de venda com o custo variável mais as despesas varáveis, e a partir disso é deduzido o custo fixo para chegar então ao resultado que é o lucro que a empresa procura (Martins, 2018). Segundo Martins (2018), a fórmula para calcular a margem de contribuição é:

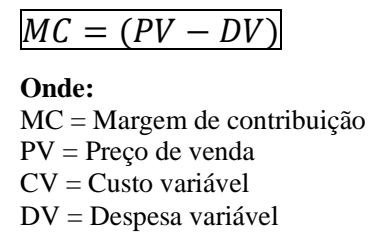

Ainda de acordo com Martins (2018), os preços de venda podem ser fixados com base nos custos, no valor de mercado e/ou baseado na combinação de ambos.

Conforme Ribeiro (2015), o preço de venda possui basicamente três elementos, sendo custos, despesas e lucro, observando que na fórmula pelo custeio variável o custo variável unitário é o único elemento que é identificado com mais segurança em unidade monetária (\$), enquanto custos fixos, despesas fixas e variáveis e a margem de lucro unitário em percentuais, então a formula desdobrada é essa:

$P V U=C V U+D V U+D F U+M L U$

Onde:

PVU = Preço de venda unitário

CVU = Custo variável unitário 
$\mathrm{CFU}=$ Custo fixo unitário

DVU $=$ Despesa variável unitária

DFU = Despesa fixa unitária

$\mathrm{MLU}=$ Margem de lucro unitária

Nesta sessão são apresentados os dados obtidos por meio da entrevista realizada com os gestores e responsáveis pelas indústrias de confecções e comércios atacadistas de utilidades de Cacoal e Pimenta Bueno, em Rondônia.

\subsection{Segmentos de atuação das empresas}

É observado no Gráfico 1 que a maioria dos entrevistados foi do segmento de indústrias de confecções, com 72,7\% dos entrevistados, contra 27,3\% dos entrevistados do segmento de atacado de utilidades. Os dados adquiridos clarificam bem o que Horácio (2018) identifica quando diz que as indústrias do ramo de confecção vêm tendo um grande crescimento na cidade de Cacoal - RO, movimentando a economia e gerando empregos.

Vale destacar também a força das indústrias de confecções da cidade de Pimenta Bueno - RO, pois de acordo com os dados pesquisados por Santos (2017) esta cidade se destaca por ser um dos maiores polos de indústria de vestuário do estado de Rondônia, assim contribuindo para o crescimento deste setor no estado.

Gráfico 1: Quantidade de Indústrias de confecções e Atacados de utilidades.

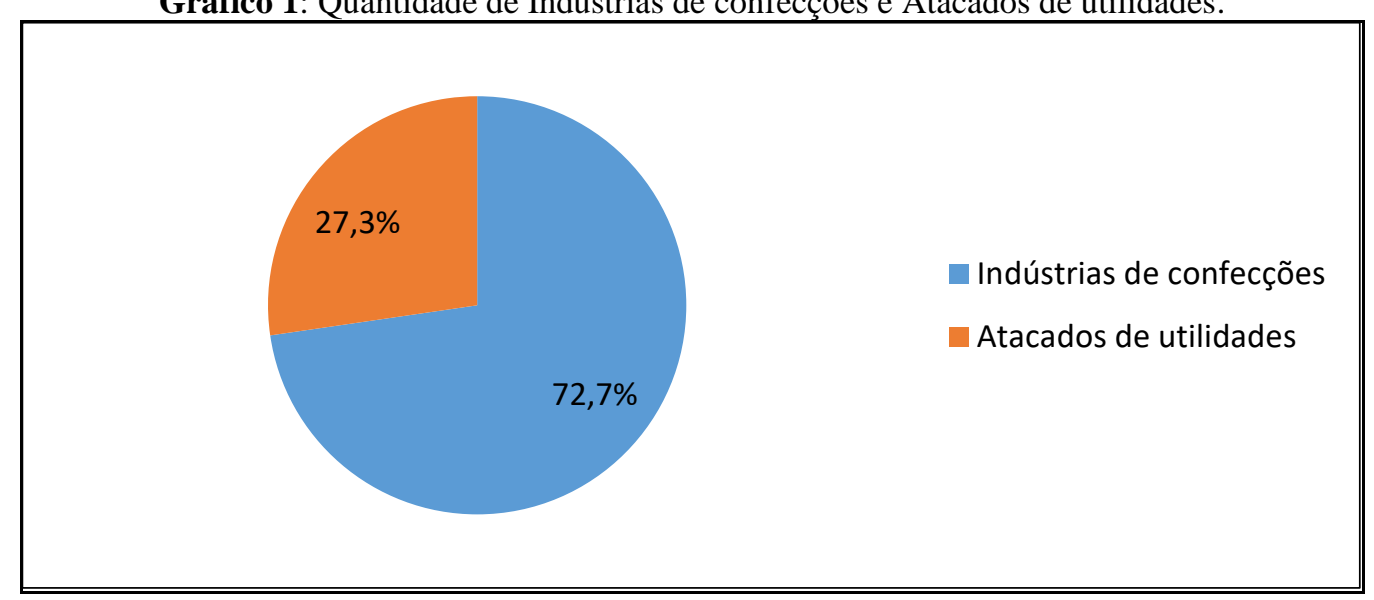

Fonte: Dados da pesquisa (2021).

As empresas de atacados são comerciais, e a princípio quando comparadas com as organizações industriais não é vista aos olhos leigos a necessidade da contabilidade de custos, mas todo processo, por mais que não seja uma empresa industrial, há a necessidade de ter esse controle. Segundo Martins (2018), por todo o contexto histórico da contabilidade de custos muitos acreditam que ela só é aplicada nas indústrias, mas inúmeras companhias de serviços, comércio e financeiras também passaram a utilizar da técnica e das mesmas terminologias para um melhor desempenho.

\subsection{Tempo de atuação da empresa no mercado e faturamento anual}

As empresas pesquisadas demonstram ter uma experiência considerável no mercado, pois como observamos na Gráfico 2, foi perguntado qual o tempo de atuação das mesmas, mostrando que em sua maioria, em um total de 90,9\% das organizações entrevistadas terem mais de 11 anos de atuação, seguindo com 9,1\% de atividade entre 01 a 05 anos e não havendo nenhuma entidade, objeto da pesquisa, com operação entre o período de 06 a 10 anos. 
Gráfico 2: Tempo de Atividade das Empresas.

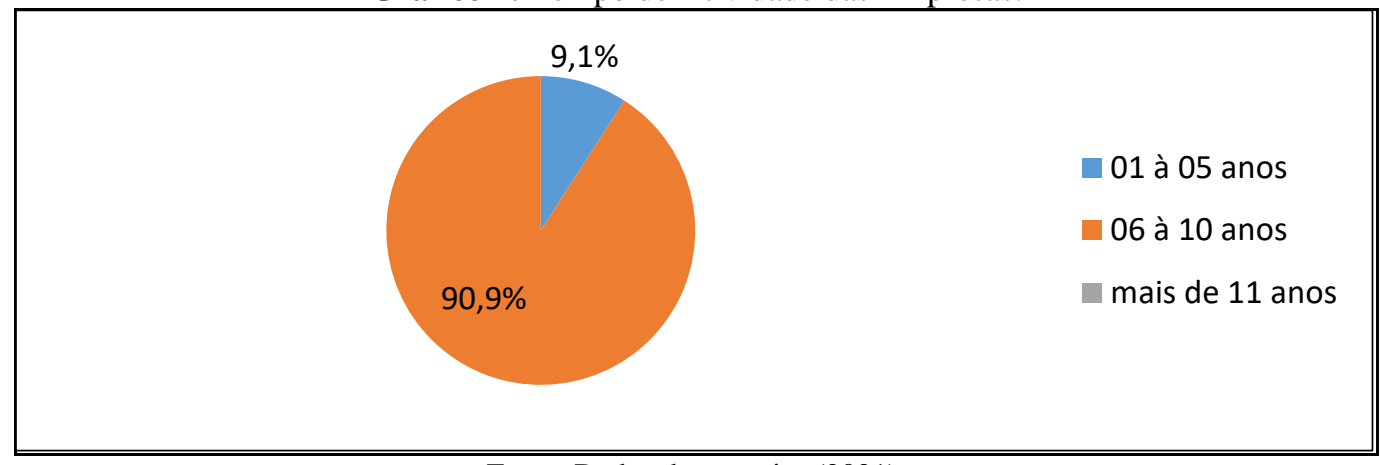

Fonte: Dados da pesquisa (2021).

O número expressivo de organizações com mais de 11 anos de atuação, vai na contramão no que diz a respeito à mortandade prematura das empresas. De acordo com pesquisa realizada pelo SEBRAE (2020), 30\% das empresas do segmento de comércio encerram suas atividades em até 5 anos, seguido pela indústria da transformação com 27,3\%, serviços com 26,6\% e por fim indústria extrativista com $14,3 \%$.

Dando sequência na entrevista foi perguntado o valor médio do faturamento anual das entidades, onde foi possível observar que $45,5 \%$ das empresas entrevistadas possuem um faturamento de até $\mathrm{R} \$ 300.000,00$, seguido de $27,3 \%$ com faturamento entre $\mathrm{R} \$ 300.000,00$ à $\mathrm{R} \$ 1.000 .000,00$ e por fim os outros 27,3\% com faturamento entre $\mathrm{R} \$ 1.000 .000,00$ à $\mathrm{R} \$ 5.000 .000,00$.

Com os resultados que se pode observar que em grande maioria as entidades pesquisadas possuem um faturamento na classificação de microempreendedores individuais (MEI) e microempresas, e segundo pesquisa do SEBRAE (2020), companhias que configuram nesses dois portes tem uma a maior tendência de fechar as portas nos primeiros 5 anos totalizando $29 \%$ para microempreendedores individuais (MEI) e 21,6\% para microempresas.

A gestão das empresas sempre será essencial para a permanência no mercado, e as informações contábeis são de grande importância para isso. Através dessas bases os gestores podem tomar decisões para um melhor planejamento, controle e execução das funções empresariais, alcançando o êxito organizacional para seguir as melhores alternativas para uma melhor administração (Santos et al., 2020).

De acordo com Bohn et al., (2018) a falta de gestão nas organizações do Litoral Norte de Santa Catarina tem sido o motivo da falência precoce dos estabelecimentos, onde os motivos principais da pesquisa mostram que a falta de conhecimento gerencial e também tributário é a causa que duplica as chances das entidades encerrarem suas atividades nos três primeiros anos.

\subsection{A utilização (ou não) dos serviços do profissional de custos}

O contador especializado em custos vem aumentando sua participação nos processos dentro das empresas de forma significativa nos últimos anos, em que pese ser ainda muito aquém do desejável e mesmo possível. Segundo Martins (2018), a preocupação inicial da contabilidade de custos para os contadores, auditores e fiscais era apenas de facilitar a mensuração monetária dos estoques e dos resultados, e não de utilizá-la como uma ferramenta da administração, e por esse motivo a contabilidade de custos deixou de ter uma evolução grande ao longo dos anos.

Foi indagado aos entrevistados se utilizavam mão de obra de algum profissional de custos e como mostra o Gráfico 3 os resultados mostraram que há necessidade de avançar nesse nicho de mercado. Dos entrevistados, 18,20\% disseram que utilizam mão de obra de profissional de custos contratado em suas organizações, 36,40\% não utilizam mão de obra de nenhum profissional de custos e 45,50\% têm mão de obra de um contador de custos por meio de parceria com o SEBRAE. 
Gráfico 3: Utilização de mão de obra de profissional de custos.

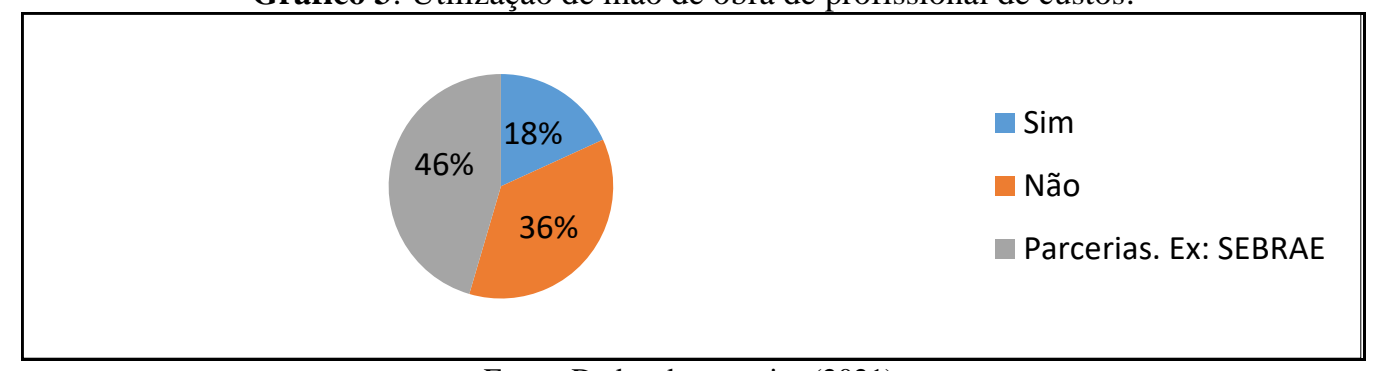

Fonte: Dados da pesquisa (2021).

Aos que responderam sim, também foi perguntado qual o nível de instrução destes profissionais, sendo verificado que $40 \%$ são graduados e os outros $60 \%$ dos profissionais são de nível especialista.

A informação da contabilidade de custos, que acompanha o desenvolvimento dos processos de custos dentro das organizações, é de grande importância para a mesma, pois através desses dados as decisões são tomadas de forma mais assertiva. O contador de custos gera os dados que as organizações necessitam para o melhor desempenho, e este profissional é imprescindível para manter um controle com eficácia (Madeira, Barros \& Portugal, 2013).

A empresa que possui o controle de seus custos tem todas as condições para exercer uma gestão com excelência, pois as bases que a contabilidade gera aos gestores os auxiliam na tomada de decisão, fazendo com que a entidade tenha condições de se tornar mais competitiva (Santos et al., 2020).

Seguindo os resultados das indagações, o motivo da necessidade da empresa precisar contratar um profissional de custos, e como pode ser observado que $6,80 \%$ das respostas foram pelo motivo da otimização no controle financeiro e formação do preço de venda, e esse resultado entra de acordo em comparação a pesquisa de Faria, Silva e Cerqueira (2017), onde ele questiona se o empresário possui dificuldade na formação do preço de venda de seus produtos, chegando ao resultado de $75 \%$ possuir dificuldade para a precificação de seus produtos, isso mostra a importância que um profissional tem no mercado.

Seguindo com os resultados, $20 \%$ dos entrevistados disseram que contrataram o profissional de custos para o controle dos custos e despesas das mercadorias e produção, e nenhuma resposta para a opção de organizar o controle e logística do estoque. Diante disso é visto que grande parte dos empresários ainda possui a visão de resultado e não no desenvolvimento do processo (Lopes e Martins, 2018).

Gráfico 4: Motivo que leva a empresa a necessitar de um profissional de custos.

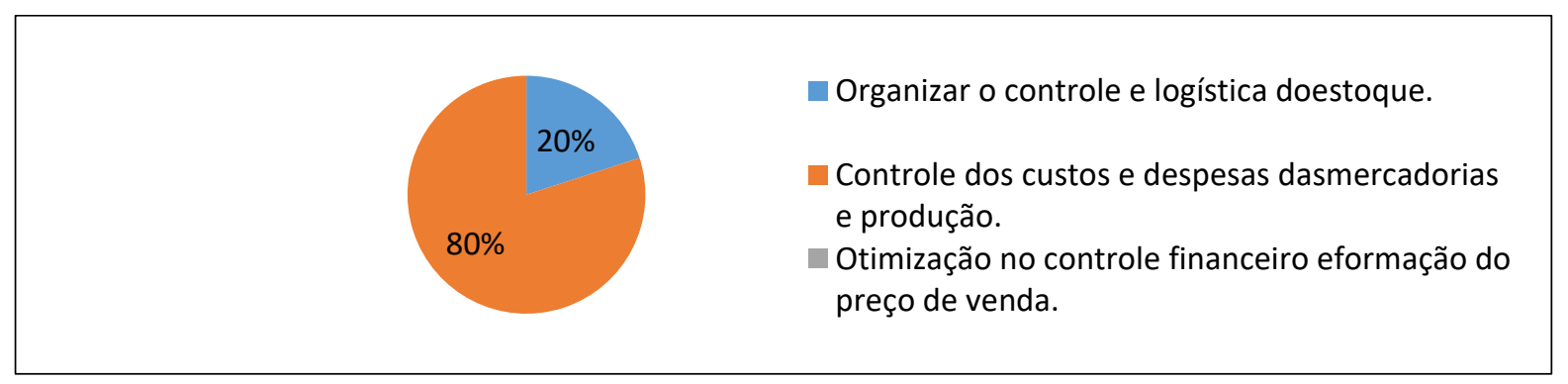

Fonte: Dados da pesquisa (2021).

A não utilização de mão de obra de um profissional de custos pode gerar deficiências no controle dos dados da produção nas indústrias ou no controle de entrada e saída de mercadorias no caso dos atacados. Segundo pesquisa de Ribeiro et al., (2020), a falta de conhecimento direto sobre o modelo de gestão que a contabilidade de custos oferece é a maior causa das empresas de pequeno porte não possuírem um profissional. 
O porte das empresas é o motivo mais forte para que essas organizações não contratem profissionais de custos, por não terem uma estrutura que seja compatível com a necessidade. Por isso foi perguntado a razão de não contratarem um contador de custos, sendo constatado que $40 \%$ diz que não necessita, pois o próprio gestor faz o controle dos dados que precisa, e $60 \%$ pelo motivo de não possuir um porte que necessite dos serviços de um profissional de custos.

Outro dado interessante são as empresas que buscam parecerias para utilizar os serviços de um contador de custos, oferecendo assim uma ótima opção para as organizações que não possuem porte para manter um profissional em seu quadro de funcionários.

De acordo com Martins (2018), departamento é um setor administrativo para a contabilidade de custos, e um departamento em grande parte das vezes é um centro de custos, pois nele são alocados os custos do setor que se encontra.

O centro de custos dentro de uma empresa é importante para uma melhor organização dos dados que serão apresentados. Como pode ser observado no Gráfico 5 , as organizações que disseram possuir um centro de custos foram apenas $20 \%$ da amostra, seguida de $30 \%$ que dizem possuir um centro de custos terceirizado e totalizando em grande maioria, chegando a $50 \%$ da mostra, dizem não possuir um centro de custos.

Gráfico 5: Departamento dedicado à contabilidade de custos.

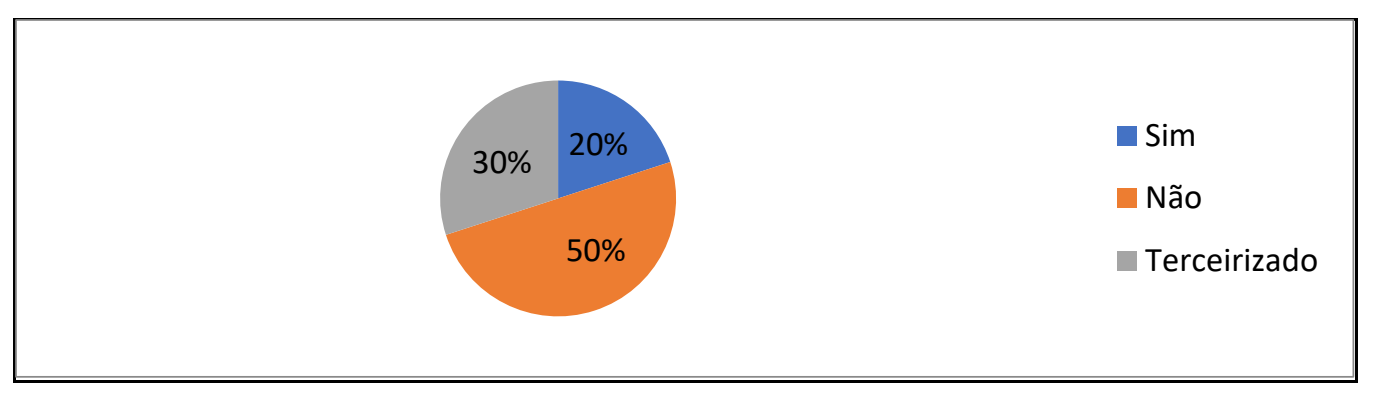

Fonte: Dados da pesquisa (2021).

O alto número de empresas que não possuem um centro de custos se deve muito por ser de grande maioria microempresas, e isso leva com que não tenham porte suficiente para tal departamento. De acordo com pesquisa realizada nas micro e pequenas indústrias do setor de confecção da cidade de Dourados - MS por Lopes e Martins (2018), nenhuma das entidades entrevistadas possuía um centro de custos, por serem microempresas, o seu faturamento e número de funcionários não são compatíveis para tal estrutura.

\subsection{Satisfação do empresário com serviço prestado pelo profissional de custos}

Por fim, de acordo com Martins (2018) a contabilidade de custos nesse novo campo chamado gerencial possui três funções: auxilio no planejamento, ao controle e na ajuda para tomada de decisão. A partir disto, nota-se que a contabilidade de custos tem cada vez mais aumentado a sua importância para a gestão das empresas.

Com isso, quando perguntado aos gestores das companhias, que havia contratado um profissional de custos, qual a maior vantagem encontrada nessa contratação, $100 \%$ dos entrevistados escolheram como opção; melhor obtenção de dados para tomada de decisão, ficando assim a opção, melhor retorno financeiro e mais organização nos processos e logísticas com nenhuma escolha.

Junto a isso, também foi perguntado se os resultados da organização melhoraram com a contratação do profissional de custos, e 100\% dos entrevistados disseram que sim, os resultados melhoram após a contratação desse profissional.

De acordo com Melo e Leone (2015), a competitividade que a entidade possui não pode ser medida somente pela capacidade de produção, mas também pelas habilidades de estratégia empresarial, e quando a empresa possui controle e dados 
corretos, a gestão adquire melhores condições de mirar a estratégia correta para o sucesso da organização, trazendo assim melhores resultados.

\section{Considerações Finais}

A informação é a melhor arma que uma empresa pode utilizar para que possa construir a melhor estratégia, buscando melhores alternativas para se sobressair diante da concorrência, e isso pode ser alcançado usando as ferramentas corretas, sendo uma delas a contabilidade de custos.

Como se observa dos resultados obtidos na presente pesquisa, o mercado para o profissional de custos nas cidades de Cacoal - RO e Pimenta Bueno - RO tem muito a evoluir, pois o número de empresas que não utilizam os serviços destes profissionais ainda pode ser considerado alto, mostrando assim que é necessário um trabalho com mais intensidade para conhecimento dos empresários acerca das vantagens que podem ter usufruindo dos serviços destes profissionais.

$\mathrm{O}$ fato da maioria das organizações que compõem o universa da pesquisa serem microempresas pode dificultar o entendimento da real necessidade de terem um profissional de custos no seu quadro de funcionários, pois em sua grande maioria não possuem porte para isso, mas algo que algumas das empresas entrevistadas fazem uso e que são de grande valia são as parcerias estabelecidas com o SEBRAE, mostrando assim que por mais que não possuam a estrutura necessária para manter um profissional fixo na empresa, utilizam dos seus serviços de consultorias por meio de tais parcerias firmadas.

Outro ponto que merece atenção é o motivo pela qual as empresas procuram pelos serviços de um profissional de custos, onde a maior parte argumenta buscar esses serviços para ter um melhor controle financeiro e para a formação do preço de venda, onde se constata que muitas organizações necessitam que haja um controle melhor em seus custos, despesas e gastos para que não resulte em prejuízos na produção ou na logística envolvida nos processos de compra e venda de seus produtos.

É importante destacar na pesquisa foi verificado que as empresas que contam com um profissional de custos estão satisfeitas com o resultado obtido, expondo assim as vantagens oriundas da inclusão do profissional desta área no quadro de funcionários da organização de modo a prestar um serviço mais direcionado e de acordo com as peculiaridades e demandas desta.

\section{Referências}

Bohn, Gambirage. C., Silva, J., Hein. N., \& Iargas. A. M. (2018). Fatores que impactam no encerramento prematuro de empresas de pequeno porte. Navus: Revista de Gestão e Tecnologia. Logroño, Rioja, Espanha, Vol. 8, num. 2, págs. 43-56. https://dialnet.unirioja.es/servlet/articulo?codigo=6570369.

Carvalho, M. P., \& Mota. K. M. (2019). Análise de custos e formação de preço de venda: estudo aplicado em uma indústria de ração. XXVI Congresso Brasileiro De Custos, Curitiba-PR. https://anaiscbc.emnuvens.com.br/anais/article/view/4621/4639.

Casado. J. H. M., Paulino. V. A., \& André. J. S. (2018). O profissional de custos e as competências buscadas pelas empresas em anúncios de emprego. XXV Congresso Brasileiro De Custos, Vitória-ES. https://anaiscbc.emnuvens.com.br/anais/article/view/4449/4450.

Comitê de Pronunciamentos Contábeis - CPC. (2009). CPC 00 (R1). http://static.cpc.aatb.com.br/Documentos/573_CPC00(R2).pdf.

Comitê de Pronunciamentos Contábeis - CPC. (2009). CPC 26 (R1). http://static.cpc.aatb.com.br/Documentos/312_CPC_26_R1_rev\%2014.pdf.

Corrêa. C. S., Shio. E., \& Santos. L. A. (2017). O Desempenho Organizacional Por Meio Da Contabilidade Gerencial Quanto A Utilização De Ferramentas De Gestão. Disciplinaram Scientia. Santa Maria-RS, v. 12, n. 1, p. 43-63. DOI: https://doi.org/10.37778/sa.v13i1.2349. https://periodicos.ufn.edu.br/index.php/disciplinarumSA/article/view/2349.

Faria. J. S. J., Silva. M. H. S., \& Cerqueira. P. G. (2017). Formação do preço de venda: uma análise nos minimercados de Pedro Canário - ES. Trabalho de Conclusão de Curso apresentado ao Curso de Administração da Faculdade Vale do Cricaré. São Mateus - ES. https://repositorio.ivc.br/handle/123456789/184.

Filho. J. L. J. X., Moura. V. J. (2016). Informação contábil e tomada de decisão: evidências de uso em uma organização industrial de médio porte. RMC, Revista

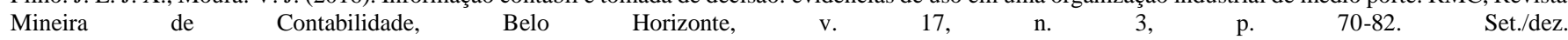
https://revista.crcmg.org.br/index.php?journal=rmc\&page=article\&op=view\&path\%5B $\% 5 \mathrm{D}=389 \& \mathrm{path} \% 5 \mathrm{~B} \% 5 \mathrm{D}=415$.

Gerhardt. T. E., Silveira. D. T. (organizadores). (2008). Métodos de Pesquisa. Coordenado pela Universidade Aberta do Brasil - UAB/UFRGS e SEAD/UFRGS. Gil. A. C. (2019). Métodos e técnicas de pesquisa social. 6. ed. - São Paulo. Atlas. 
Gimenez. L., Oliveira. A. B. S., \& Carvalho. F. J. P. (2018). Pesquisa ação: implantação da contabilidade de custos e gerencial para suporte do processo decisorial em um call Center. REDECA Revista Eletrônica do Departamento de Ciências Contábeis \& Departamento de Atuária e Métodos Quantitativos da FEA, v.5, n.2., p. 48-63, Jul-Dez. https://revistas.pucsp.br/index.php/redeca/article/view/40845/27586.

Horácio. J. S. (2018). Planejamento estratégico: um estudo multicaso em indústrias de confecções do município de Cacoal. Trabalho de Conclusão de Curso (Bacharelado Administração) - Universidade Federal de Rondônia. Cacoal - RO. http://www.ri.unir.br/jspui/handle/123456789/2557.

Klein. D., Alves. A. P. F. (2016). Análise da implantação de um sistema de custos: O Caso De Uma Empresa Metalúrgica. Revista Gestão Premium, Osório-RS, v. 5, n. 1, P. 28-49. http://sys.facos.edu.br/ojs/index.php/gestao/article/view/52/40.

Lopes. A. C. V., Martins. L. A. (2018). Gestão de custos nas micro e pequenas indústrias do setor de confecções da cidade Dourados - MS. Anais Do Congresso Brasileiro De Custos - ABC. São Leopoldo - RS. https://anaiscbc.emnuvens.com.br/anais/article/view/4588.

Madeira. F., Barros. P. M. J., Portugal. G. T. (2013). A utilização do custo padrão em uma indústria de médio porte: o caso da empresa aerojet1. Revista de Contabilidade do Mestrado em Ciências Contábeis da UERJ (online), Rio de Janeiro, v. 18, n.3, set/dez. http://www.atena.org.br/revista/ojs-2.2.308/index.php/UERJ/article/view/1904/1750.

Martins. E. Contabilidade de custos. 11. Ed. São Paulo: Atlas, 2018.

Melo. M. A., Leone. R. J. G. (2015). Alinhamento entre as Estratégias Competitivas e a Gestão de Custos: um Estudo em Pequenas Empresas Industriais do Setor de Transformação. BBR - Brazilian Business Review, Vitória - ES, vol. 12, núm. 5, set./out. DOI: https://doi.org/10.15728/bbr.2015.12.5.5. http://www.bbronline.com.br/index.php/bbr/article/view/159.

Nerio. V. R. P. (2020). Contabilidade de Custos na Gestão Hospitalar: Um Estudo de Caso de Outsourcing no Contexto do Hospital Universitário de Juiz de Fora. São Leopoldo - RS: Leopoldo. Associação Brasileira de Custos, v. 15, n.1, p. 27-47, jan./abr. DOI: 10.47179/abcustos.v15i1.515 https://www.abcustos.emnuvens.com.br/abcustos/article/view/515/705.

Oliveira. K. R., Duarte. S. L., \& DUARTE, D. L. (2020). Custos de produção de cana-de-açúcar relacionados ao preço de exportação do açúcar. Revista Brasileira de Contabilidade, n. 241, p. 40-53, mar. http://rbc.cfc.org.br/index.php/rbc/article/view/1938.

Ribeiro. L. N., Nascimento. M. R., Bueno. T. V. A., Miranda. L. P., Querino. F. F., \& Ribeiro. F. F. Gerenciamento da contabilidade de custos pelos micro e pequenos empresários do município de Hortolândia-SP. Anais Do Congresso Brasileiro De Custos - ABC. São Leopoldo - RS, 2020. https://anaiscbc.emnuvens.com.br/anais/article/view/4781.

Ribeiro. O. M. (2015). Contabilidade de custos. 4. ed. São Paulo: Saraiva.

Rocha. J. F. A., Nobre. C. J. F., \& Araújo. R. J. R. (2018). A contabilidade gerencial no processo de tomada de decisão e o conhecimento das empresas sobre sua importância. REFAS- Revista Fatec Zona Sul, São Paulo $\quad$ - SP, v. 5, n. 2 , p. 65-76. http://www.revistarefas.com.br/index.php/RevFATECZS/article/view/231/192.

Santos. J. A. (2017). Indústrias de confecções em arranjos produtivos locais: um estudo de caso do aglomerado de confecções de Pimenta Bueno/RO. Trabalho de Conclusão de Curso (Bacharelado em Engenharia de Produção) - Universidade Federal de Rondônia. Cacoal - RO. http://www.ri.unir.br/jspui/handle/123456789/2130.

Santos. J. L., Shmidt. P., Pinheiro. P. R., \& Nunes. M. S. (2015). Manual de contabilidade de custos. São Paulo: Atlas.

Santos. L. A., Degliuomeni. M. B., Camargo. B. F., \& Guse. J. C. (2020). Proposta para implementação de ferramentas de gestão por meio da contabilidade gerencial. Rev. Bras. de Iniciação Científica (RBIC), Itapetininga-SP, v. 7, n.1, p. 166-191, jan./marc. https://periodicos.itp.ifsp.edu.br/index.php/IC/article/view/1299/1203.

Sebrae. S. B. A.M. E. (2016). Sobrevivência das empresas do Sebrae. 2020. Disponível em: https://www.agenciasebrae.com.br/asn/Estados/NA/Sobrevivenciaempresassebrae_Final.pdf. Acesso em: 13 set. 2021. Severino. A. J. Metodologia do trabalho científico. $24^{\circ}$ Ed. São Paulo: Cortez.

Silva. A. C. R. (2017). Metodologia da pesquisa aplicada a contabilidade. UFBA, faculdade de Ciências Contábeis, Salvador-BA.

Silva. P. S., Santos. A. M. (2020). A importância da informação contábil no processo de gestão das micros e pequenas empresas. Revista Brasileira de Contabilidade, n. ${ }^{\circ}$ 241, p. 63-75, jan./fev. http://rbc.cfc.org.br/index.php/rbc/article/view/1949/1300.

Soares. C. S., Barbieri. L. W. (2017) A relação Custo/Volume/Lucro na Produção de Arroz: Um Comparativo entre o Cultivo Pré-germinado e o Plantio Direto. Associação Brasileira de Custos, São Leopoldo $\quad-\quad$ RS, v. 12 , n. $\quad 3$, p. $\quad 45-72, \quad$ set./dez.. $\quad$ DOI: $\quad 10.47179 /$ abcustos.v12i3.455, https://www.abcustos.emnuvens.com.br/abcustos/article/view/455/432.

Zahaikevitch. E. V., Tozeto. V., Gura. A., Silvério. A. C., \& Bittencourt. J. V. M. (2018). Contabilidade gerencial no processo de tomada de decisão: o conhecimento dos empresários das micro e pequenas empresas. Revista Produção Industrial \& Serviços, Maringá-PR, v. 05, n. 02, p. 126-141. http://periodicos.uem.br/ojs/index.php/rev_prod/article/view/52419.

Zanin. A., Magro. C. B. D., Mazzioni. S. (2019). Características organizacionais e a utilização da gestão de custos no processo decisório. Revista Catarinense da Ciência Contábil, Florianópolis - SC, v. 18, p. 1-19. http://revista.crcsc.org.br/index.php/CRCSC/article/view/2793/2082.

Zuccolotto. R., Filho. E. C. (2007). Gerenciamento de preços em empresas de pequeno porte por meio do custeio variável e do método de Monte Carlo. Enfoque: Reflexão Contábil. Maringá-PR, vol. 26, núm. 3, p. 39-52, set./dez. https://www.redalyc.org/articulo.oa?id=307124256003. 